\title{
To mandatory nap or not to mandatory nap
}

Published at www.cmaj.ca on Jan. 5

I t's safe to conclude that most people would not take issue with a requirement that they take a nap at some point during their workday. The United States Institute of Medicine even urges that a five-hour snooze should be made mandatory for all medical interns and residents who are putting in 16-hour shifts.

The Canadian Association of Interns and Residents, though, isn't convinced of the value of mandatory naps. In fact, Executive Director Cheryl Pellerin says that if naps are added into contracts, they could interfere with a resident's training — he or she might miss a procedure vital to a good education.

Mandatory naps are among options being bandied about in response to growing concerns that lengthy shifts for interns and residents compromises the safety of patients. While many jurisdictions are still exploring alternatives, the European Union has adopted a maximum 48-hour workweek as its solution to the problem (CMAJ 2009. DOI:1503 /cmaj.109-3111).

The US Institute of Medicine waded into the debate with a recommendation that every resident or intern should be obliged to nap for five hours - at some point between $10 \mathrm{pm}$ and 8 am - for every 16 hours they work. During the nap, there should be no interruptions or pages, the institute says in its report, Resident Duty Hours: Enhancing Sleep, Supervision, and Safety (http://books.nap.edu/openbook .php?record_id=12508).

While interns and residents in Europe are now limited to 48 hours of work per week, the situation in the US and Canada is less stringent. In 2003, the Accreditation Council for Graduate Medical Education capped the hours a US intern or resident could work at an average of 80 hours per week over four weeks. In Canada, while regulations vary from province to province, an intern or resident generally works no more than 60 to

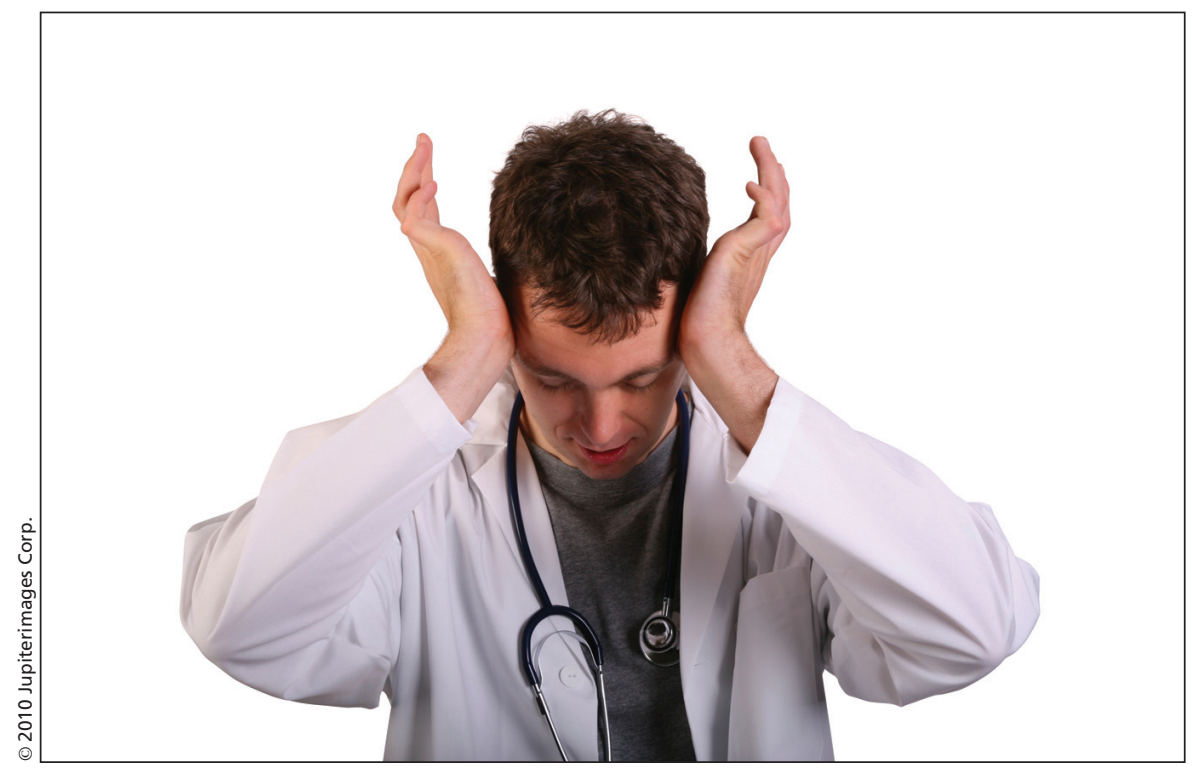

Proponents of mandatory naps argue that the safety of patients is compromised when interns and residents are exhausted and thus prone to error.

80 hours per week. Only three provinces have maximum weekly hours built into their legal contracts; Manitoba's regulations are the highest at 79 hours.

Mandatory naps would be "kind of difficult to institute," says Dr. Roona Sinha, past president of the Canadian Association of Interns and Residents. "What matters more is trying to make the person functional the day after."

Shorter shifts and more rest hours after long shifts would be preferable to mandatory naps, Sinha adds.

Pellerin concurs, saying that more effective handovers of patients as shifts change would be more significant that midshift naps. An association working committee on postgraduate medical education is currently investigating the best ways to structure handovers so that the incoming physician or resident is well informed about the patient, so that fewer mistakes are made. That review is expected to be completed early this year. While most of the concern about lengthy working hours has been focused on interns and residents, some say the scope of concern must be extended to include all physicians and surgeons.
People are wary about limiting the hours worked by physicians and surgeons but it's something that needs to be addressed, says Dr. Derek Puddester, director of the faculty wellness program at the University of Ottawa and coeditor of the Royal College of Physicians and Surgeons of Canada's CanMEDS Physician Health Guide.

Younger physicians aren't inclined to toil as many hours as their older counterparts, Puddester says, adding that the younger generation has been socialized to value work-life balance, so as they move up and become practising physicians, that ethic will likely be a condition of employment. As a consequence, he predicts limits on weekly work hours will be introduced within the next five to seven years for most doctors.

Cheryl Ulmer, coeditor of the Institute of Medicine report, concurs. "Doctors are human too," she says.

But others, such as Dr. Thomas Nasca, chief executive officer for the Accrediation Council for Graduate Medical Education, says capping work hours or introducing mandatory naps 
for physicians and surgeons isn't feasible. "Who's going to take care of the patients while we're sleeping?"

Nasca adds that the cost would be prohibitive, citing a study that indicates it would cost roughly US\$80 billion per year to train the physicians that would be needed if doctors adopted the workweek standards of airline pilots (Am J Surg. 2009;197[6]:820-5). And that doesn't take into account the notion of continuity, which is integral to effective patient care, he says.

When the Accreditation Council for Graduate Medical Education implemented an 80-hour work week limit for interns and residents in 2003, it promised a review of the guideline after five years.

The results of that review, which included a national duty hours congress, independent literature reviews and consultations with over 140 med- ical organizations, will be presented in February, Nasca says.

Thus far, it's clear from the review that the number of duty hours and nap times aren't as crucial as top-notch supervision, Nasca adds. "This is not an issue of right or wrong, it's an issue of competing goods." - Sabrina Doyle, Ottawa, Ont.

DOI:10.1503/cmaj.109-3146 